\title{
LA EXPERIENCIA DEL SUJETO CULTURAL EN LA MURGA DE PEDRO ORGAMBIDE
}

\section{Introducción}

Cuando el objeto es tan recortado lo importante es plantear el propósito en términos de la pertenencia del texto a un corpus. En este caso me ha interesado Pedro Orgambide en el marco de un conjunto de autores que, contemporánea o anacrónicamente, han ingresado el Día de la Lealtad a la escritura literaria.

En trabajos anteriores ${ }^{1}$ relevé autores como Borges, Martínez Estrada y Lamborghini que, en mayor o menor medida, textualizan el episodio del 17 de octubre de 1945, fecha en que "una cosa terminaba y otra empezaba", como expresa una novela de aquel entonces $^{2}$.

"La murga" de Orgambide es un cuento que integra Historias con tangos y corridos, libro de cuentos y relatos publicado en 1976 por Casa de las Américas de La Habana porque fue premio de ese año, sin embargo el cuento existe desde antes de integrarse como introductorio a esta veintena de textos narrativos que exceden el suelo de la patria. En el relevamiento que realiza Ernesto Goldar (1971: 43) lo cita, y desarrolla un breve comentario respecto de muchos de los autores que encasillan la visión de peronismo = carnaval.

Con un título tan referencial de ese tópico de cierto campo intelectual lo esperable sería que Orgambide se incorporara a la serie escrituraria que ejerciera - y ejerce aún una suerte de juicio estético al mal gusto de la expresión callejera de aquella jornada. Su texto en cambio se inscribe en una coordenada cuyo uso de la parodia no pretende denostar lo representado. Orgambide nos tiene acostumbrados a títulos aparentemente anticipatorios de un tratamiento sujeto a formas genéricas de los temas: Mitologías de ...; $\mathrm{Me}$ morias de ...; ; Historias cotidianas y fantásticas (1965), libros que en efecto incluyen, en forma parcial, el género anunciado en el macrotítulo, de modo que la convivencia de "La murga" con "La gata y el organillero" o "Elegía para una yunta brava" o con "Sainete", no predispone una lectura de temas propiamente históricos. Más bien desvía la expectativa hacia la acepción de "historias" en términos de ficciones o relatos anecdóticos.

\section{De la inserción a la evaluación tópica}

"La murga" por lo pronto es un texto que amerita ser considerado como típicamen-

\footnotetext{
${ }^{1}$ Me refiero a dos trabajos presentados a congresos: "Ficción y política en 'La fiesta del Monstruo' de Borges y Bioy en Actas de Jornadas sobre J. L. Borges, Universidad de Liubliana (Eslovenia), 2000; "El ensayo de ideas como intertexto de la ficción política", ponencia leída en 80. Congreso de Profesores de Español, Vittoria, Universidad Federal de Espiritu Santo (Brasil), 1999.

2 Se trata de El día de octubre de Valentín Fernando, registrada en el importante trabajo de Ernesto Goldar (1971): El peronismo en la literatura argentina. Bs. As.: Freeland.

3 Aludo a Mitologías de la adolescencia (1948), Memorias de un hombre de bien (1964) y se podría agregar Historias imaginarias de la Argentina (1986).
} 
te sesentista en cuanto a la escogencia referencial y de registro lingüístico. Tanto los estudios panorámicos que recortan la tradición narrativa con la designación de "narrativa de $1955 \ll^{4}$, como los enfoques más específicos de R. Borello (1991) y Noemí Ulla (1996) dan elementos para reconocer en este texto las marcas de lo que se dio en llamar el "realismo crítico".

En cuanto realismo la escritura de Orgambide se acoge a un referente histórico, ya impregando de referentes literarios, esto es, la repetida "crónica de una parodia anunciada", que refirieron antes otros escritores. Si por realismo entendemos el retrato social en una coordenada tempo-espacial reconocible merced a las estrategias de verosimilización, el texto aquí presentado responde al realismo. Pero cuando la versión es paródica hay que preguntarse en qué dirección apunta el atributo.

El realismo crítico de los años sesenta fue en gran medida autocrítico ${ }^{5}$, digo esto porque, si bien uno de los puntos nodales de la realidad auscultada era el peronismo en sus excesos, también se reparaba en la pertinaz sorna del rechazo a la vertiente popular del movimiento. Lo que Orgambide textualiza a priori no difiere del tratamiento ocurrido casi en sincronía al tiempo de la historia: es una crónica como lo es "La fiesta del Monstruo" de Bustos-Domeq, apela al registro coloquial con el pintoresquismo y agilidad de lo que semantiza la murga. A fortiori el cuento tiene otros ingredientes cuya clave simbólica es actorial.

La voz emitida por un narrador omnisciente desliza el relato de los hechos in praesentia -casi con matices de crónica policial-, aunque hacia el final da lugar a la conjetura: Como en toda historia, como en toda vida, los datos son imprecisos (Orgambide, 1976: 15). Antes dije que es en el nivel actorial donde puede estar la clave axiológica de un relato que aparenta neutralidad, a expensas de un discurso travestido por una suerte de liminalidad de la cronología. En esta puesta en acto de la escena de la murga el relato recurre a la confrontación de bandos: Los Indios, Los ingleses. Hay elementos cronotópicos que inducen a reconocer un Buenos Aires, siglo XX; de modo que investir a un actor colectivo del gentilicio ingleses, y atribuirles carácter de bando enemigo conlleva la microsemiótica de la génesis identitaria. Veamos:

Los que vieron aquello dicen que las mujeres y los chicos tiraban agua desde las azoteas. Los exagerados, los fanáticos, aseguran que vieron caer aceite hirviendo. (Orgambide, 1976: 11)

Dicho de otro modo: que el enemigo en la contienda representara lo contrario de la chusma, fiesta a lo criollo, boleadora pampa, los provincianos, olor a chamamé, etc., y que se identificara con la gente decente ${ }^{6}$, discursiviza el remanido tópico de cultura po-

\footnotetext{
${ }^{4}$ Se trata del cuidadoso artículo de Alfredo Rubione en Historia de la Literatura Argentina, V. 5, Bs. As.: CEAL, 1982.

5 Desarrollo esta idea en un trabajo sobre Rozenmacher realizado en coautoría: Royo y Guzmán Pinedo, "El peronismo y los cabecitas negras como representación de la migración interna", Universidad Autónoma de Baja California Sur (Mex.), 1998.

${ }^{6}$ Las murgas iban perdiendo prestigio y las comparsas ganaban el favor de la gente decente (11), la cita apunta a demostrar la asimilación a prácticas de una intelectualidad muy pregnadas por el modelo anglófilo.
} 
pular versus cultura de élite. Es inevitable en este punto relacionar la polarización de los bandos en la ficción de Orgambide con la que establece cierta crítica revisionista al configurar la díada nacionalismo/europeísmo?.

En la confluencia de la instancia subjetiva y de su manifestación colectiva Edmond Cros localiza el sitio del sujeto cultural, categoría que me resulta útil para descubrir encodificaciones de lo ideológico, en tanto raíz común de la conciencia identitaria. En el razonamiento de Cros se conjugan la noción de sujeto equivalente a la propiedad fundamental del lenguaje tal es la de constituir al sujeto en el instante de la emisión del yo. Asimismo, Benveniste mediante, Edmond Cros interpreta que yo es una forma verbal vacía hasta tanto se convierte en instancia de discurso.

Si el sujeto cultural es un avatar del sujeto ideológico y es éste el que se autorrepresenta en todo acto de representación (Cros, 1997: 46), es evidente que una escritura que intenta representar lo irrepresentable que es el carnaval ${ }^{8}$, justifica los interrogantes en torno a los móviles de poner en escena los grandes relatos, hechos de breves episodios. El ejemplo que cito es por demás elocuente:

Entró la murga en el salón de los espejos y los gordos se vieron flacos y los pobres se despertaron ricos, y de esa confusión, de esa ilusoria beatitud, el Jefe sacó una esperanza, proyectó su fe, la contagió a los suyos. (Orgambide, 1976: 14)

Para volver a la lógica actorial planteo como relevante que exista solo un personaje reconocido por su nombre -Garay-, las otras individualidades se designan por sus roles. Resulta, entonces, sintomático que Garay, nombre fundante por antonomasia, sea llamado a dirimir, mediante la autoridad policial, la primera gresca producida entre Los Indios $y$ los españoles -casi todos eran gallegos y portugueses afincados en las costas del Riachuelo-, esta acotación introduce nuevos actores que dan cuenta de otra oposición: nativos vs. inmigrantes. Con un fundador devenido propietrio de bar y un místico víctima de una boleadora pampa, se podría hipotetizar que el recurso paródico incurre en descoronamiento ${ }^{9}$ de la gesta colombina.

Ahora bien, cuando un texto no se emite desde la identidad incuestionable del yo -como ocurre en el caso aquí expuesto-, el sujeto puede hacerse presente bajo otras formas que permiten el reconocimiento de la doxa o de los ideologemas. Hay en este texto dos ideologemas posibles: el que homologa peronismo a circo, carnaval, murga y el que propone peronistas equivalente a bárbaros, por ello el texto transcribe un hito paradigmático de esa morfogénesis:

\footnotetext{
${ }^{7}$ Cf. Ramos, Abelardo (1957): Crisis y resurrección de la literatura argentina. Bs. As.: Indoamérica, y Hernández Arregui (1973): La formación de la conciencia nacional. Bs. As.: Plus Ultra.

8 En palabras del sociocrítico francés: "El carnaval, se vive como una fusión en lo colectivo. La máscara misma es el vector de esta fusión: borra el rostro y gracias a ella el individuo se esconde tras una función mítica o social" (Cros, 1997: 47).

9 Cf. Bajtín (1988): La cultura popular en la Edad Media y el Renacimiento. El contexto de François Rabelais. Madrid: Alianza.
} 
Algún cajetilla (nunca faltan críticos cuando un pobre se diviete) frunció el ceño ante el espectáculo. "Paciencia -dijo el Jefe- él se la buscó". En broma como quien no quiere la cosa le bajaron los pantalones y le escupieron alá donde usted sabe ... (11)

Según la sociocrítica los ideologemas pueden patentizar el estadio más ostensible del sujeto cultural. Por lo tanto: en vista de que el sujeto cultural es el resultado de que el agente de identificación sea la cultura y no el sujeto, es claro que un texto, cuyo enunciado refiere episodios y actores mitificados/desmitificados alternativamente, la enunciación debería ser la portadora de ese plus intrapsíquico que posiblemente coincide con el sujeto del deseo en términos de Lacan ${ }^{10}$.

Hasta aquí no aparecen las evidencias ciertas de que lo textualizado sea el 17 de octubre como lo anticipara al comienzo, la diégesis se reduce a relatar el avance de la murga de Los Indios hacia la ciudad, en su desplazamiento chocan primero, en el bar con los españoles y luego con la comparsa de Los Ingleses: esos eran carnavales, no los de ahora, comenta el narrador en una modelización que parece tomar distancia del relato de los hechos.

Si bien las actancias que protagonizan el objeto de la crónica ya fueron localizadas, los roles de director y la mujer del director son, tal vez los decisivos como clave de interpretación, se trata pues del director o jefe de la murga, en cuya caracterización se filtran evidencias de identidad", pese a la enunciación en sordina - ... mientras el director con su lanza [...] señalaba a lo lejos el resplandor de la fiesta - esta subordinada es la secuencia con la que empieza y concluye el texto. Digo secuencia porque, a esta altura, ya alcanzo a develar que lo que en principio parece la crónica de una jornada de carnaval, día preciso de la confrontación de la murga con sus oponentes, ha mutado en la metonimia de la historia argentina. El carnaval con su simbología funciona como la representación de un largo proceso que se inicia con la conquista y desemboca en un día que se convierte en gozne y sinceramiento de identidades: los Indios refrescaban sus pies en las fuentes de la Plaza, pedian a su Jefe que, en el tumulto, había desaparecido y, según decian, estaba prisionero (14). Es la historia del peronismo, aunque la murga no es simplemente denotativa del 17 de octubre, ni el carnaval connota el movimiento en una dimensión plana y pedestre.

En efecto, sugiero que los rasgos de enunciación en los que se filtra la subjetividad se articulan con lo dicho de manera casi indiferenciable, como ocurre en la última cita; sin embargo debo admitir que otro segmento retativo al Jefe - sacó una esperanza, proyectó su fe, la contagió a los suyos (14) - tiene un matiz coincidente con la construcción (ya citada) que abre y remata el cuento.

\footnotetext{
${ }^{10}$ Se hace necesario explicar que la remisión a Lacan es una consecuencia de usar como marco teórico la propuesta de Cros. Su postulación del sujeto cultural se alimenta de Benveniste y de Lacan, en lo relativo a la emergencia del sujeto. Cf. "El sujeto cultural: de Emil Benveniste a Jacques Lacan", en Cros (1977): El sujeto cultural. Sociocrítica y psicoanálisis. Bs. As.: Corregidor.

${ }^{11} \mathrm{La}$ identidad de Perón se patentiza por la caracterización de su mujer que es llamada La Madre por sus seguidores. Esta figura es la de mayor carga de semas pasibles de reconocimiento: está rodeada de niños y viejitos. Se asegura que alguien robó el cuerpo embalsamado de la Madre ... (Orgambide, 1976: 15)
} 
La escritura mueve muchos hilos hasta mostrar un reverso de la trama que me permite volver sobre la complejidad del sujeto cultural ya considerado. Si efectivamente $e l$ agente de identificación es la cultura, no el sujeto - como sostiene Cros (1997: 18) frente a la ocurrencia de una nueva textualización del 17 de octubre de 1945, estoy ante un dilema al proponer que la cultura nacional no es homogénea, toda vez que el mismo episodio histórico dio lugar a variados registros: burlescos, irónicos, elegíacos, fantásticos, con sus respectivas huellas de axiología.

En esta versión de Pedro Orgambide coexisten dos microsemióticas: una que parece coincidir con los escritores del grupo Sur, es decir la visión apocalíptica de describir el carnaval como el avance de la barbarie, en la posibilidad de un nazismo a la criolla; la otra que, de manera mucho más disimulada, hace lugar al encomio. Da pruebas de esta última el campo semántico de la esperanza textualizado en la cadena lexemática "avanzaban", "resplandor"; "A lo lejos"; "marcna"; (el baile) "siguió"; "siguió" (la fiesta); "gozosos"; "nacieron" (los cantos); "júbilo", "futuro", etc. La cadena se articula con la imagen de $L a$ Madre - siempre rodeada de viejitas y de niños - construcción que podría leerse como la incorporación paródica de la que proyectaba la propaganda en tanto aparato partidario, conlleva sin embargo la que el mismo Orgambide materializa cuando reflexiona sobre el ser argentino $^{12}$ en su conflictiva relación social con Eva Perón. Veamos:

La vida y la muerte de una mujer entraban ya en el dominio de la mitología popular [...] Dios estaba con ella o contra ella. El Dios de los burgueses, de los antiperonistas, de los contreras no movería un dedo para salvarla. El Dios festivo de los días peronista, el Dios de los ranchos y el suburbio debía amparar entonces a la hermana, a la madre de los humildes, a la santa, como pedía el pueblo. (Orgambide, 1996: 211)

Es evidente que a esta altura el análisis del sujeto cultural locutado en el texto "La murga" debe hacer lugar al que se expresa en otros productos del autor entre los que aparece su visión de los intelectuales frente al peronismo. En ese registro Orgambide sitúa en la mira la narrativa de un "contra" como lo fuera Martínez Estrada y apela al mismo recurso que empleo yo aquí, es decir, pone en diálogo el ensayo (visión reflexiva) con la ficción (forma de la búsqueda). Consciente de que no es propósito de esta comunicación dar cuenta de esa analogía entre un segmento de Radiografía de la pampa (1933) y "Sábado de gloria" (cuento posterior a 1943), me limito a mostrar que Pedro Orgambide se posiciona al considerar la actitud irreductible de un Borges, frente a la flexibilidad evidenciada por Martínez Estrada cuando después del ' 55 vindica tenuemente al peronismo derrotado.

El posicionamiento señalado se expresa claramente en la siguiente cita:

El pueblo, precisamente, no tenía por qué avergonzarse [...] había visto cumplidas viejas reivindicaciones de nuestra clase obrera, y más allá de su proyecto de clase [...] podía compar-

\footnotetext{
${ }^{12}$ Aquí la fuente es el libro del mismo autor titulado Ser argentino, Bs. As.: Temas Grupo Editorial, 1996, donde fragmentariamente se ocupa del tango, el peronismo, Gardel y Eva Perón, entre muchos otros temas que permiten seguir el derrotero de nuestros encuentros/desencuentros históricos.
} 
tir con su gobierno las premisas básicas [...]. El pueblo precisamente estaba fuera de toda sospecha. (Orgambide, 1996: 185)

Consideración que me insta a volver sobre páginas anteriores cuando (supra nota 5) hice referencia al realismo crítico. El aserto de que en los años sesenta la escritura tuvo marcas de una conciencia autocrítica refuerza lo dicho sobre la heterogeneidad del sujeto cultural en el caso argentino.

\section{Conclusión}

La aparente homogeneidad de tratamiento del mismo tema suscita la ilusión de un sujeto cultural adverso al peronismo y a sus históricas expresiones condensadas en gestos populares. Verificar que esa apariencia es a veces usada para otra valoración de los hechos y de los líderes del 17 de octubre de 1945, conduce a concluir que cualquier escritura de ficción se impregna de la experiencia dominante en el campo intelectual, en este caso adversa al objeto de representación.

Es en la enunciación del narrador donde se reconocen las huellas de un otro del sujeto cultural, otro, en el caso de Orgambide proclive a identificarse con la turba en tanto cultura popular, ámbito donde también abreva la identidad nacional.

\section{Bibliografía}

Borello, Rodolfo (1991): El peronismo (1943-1955) en la narrativa argentina. Universiy of Ottawa, Canadá.

Cros, Edmond (1992): Ideosemas y morfogénesis del texto. Frankfurt: Vervuert.

Cros, Edmond (1997): El sujeto cultural. Sociocrítica y psicoanálisis. Bs. As.: Corregidor.

Orgambide, Pedro (1976): Historias con tangos y corridos. La Habana: Casa de las Américas.

Ulla, Noemí (1995): La insurrección literaria. Bs. As.: Torres Agáero ed.

\section{IZKUŠNJA KULTURNEGA SUBJEKTA V PRIPOVEDI LA MURGA PEDRA ORGAMBIDEJA}

Članek predstavlja argentinskega esejista, kritika, novinarja in pisatelja Pedra Orgambideja (1925-2003) in njegovo pripoved "La murga" (Poulična godba). Izhajajoč iz teoretskih stališč Edmonda Crosa razčlenjuje Orgambidejevo pripoved, ki opisuje zgodovinski dan 17. oktober 1945 (Día de la Lealtad - Dan vdanosti), ko so se ljudske množice zbrale na ulicah in podprle Peróna ter mu tako omogočile, da je prevzel oblast. Dogodki tega dne so opisani kot kronika, vendar $\mathrm{z}$ določeno mero ironije, prikazani so kot karneval, ki v sebi nosi srž tragedije. 